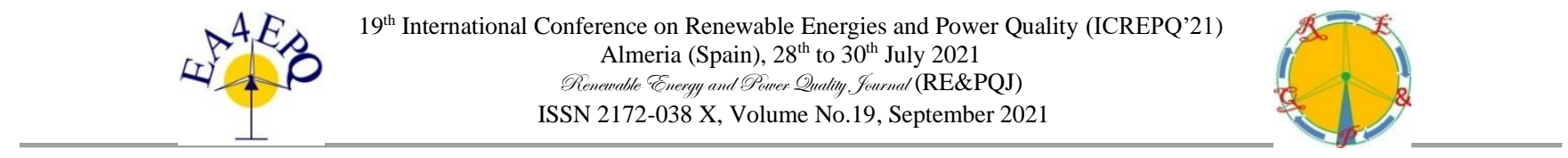

\title{
Adaptive Notch Filter based WECS for Unbalance Mitigation
}

\author{
M.K. Abbas, M. Mokhtar, M. I. Marei, and A.A.El-Sattar \\ Department of Electrical Power and Machines \\ Faculty of Engineering, Ain Shams University \\ Cairo, Egypt \\ e-mail: merna.khaled@eng.asu.edu.eg
}

\begin{abstract}
The accelerating spread of distributed energy resources among the LV networks has revealed their adverse impact on voltage profiles, power quality and protections along the network. On the contrary, since they are essentially interfaced with the network through power electronic converters that can be exploited to enhance power quality. Voltage regulation, unbalance and harmonics mitigation are some examples of the functions that can be implemented through these converters. This paper presents a wind energy conversion system (WECS) with a back-to-back converter performing its mere function of maximizing wind energy capture and regulating output active and reactive power. Added to these basic functions, ancillary services are provided to a local load and MV grid. Voltage regulation of the load voltage at different loading conditions is achieved. Extraction of load unbalance is investigated through different algorithms. Adaptive Notch Filter (ANF) has demonstrated a leading response over the conventional methods in detecting the symmetrical components under different unbalance conditions. Unbalance in grid currents is then effectively managed and the currents from/to the MV grid are ensured to be balanced. The system is simulated using PSCAD/EMTDC and results are presented to confirm validity of the proposed methods.
\end{abstract}

Key words. Wind Energy, Tertiary Transformer, Voltage Regulation, Unbalance Mitigation.

\section{Introduction}

Wind energy conversion systems (WECS) have become of a significant importance due to their improved flexibility. Variable Speed Wind Turbines (VSWTs) are used to track the maximum power point (MPP); thus, leading to maximizing the output energy. Recently, VSWTs usually incorporate gear-less Permanent Magnet Synchronous Generator (PMSG). PMSG has exceeded the Doubly Fed Induction Generator (DFIG) considering its efficiency and elimination of the gear box. Additionally, back-to-back (B2B) voltage-controlled converters is the most commercialized topology for interfacing WECS with the grid [1]. The VSWT interaction dynamics with the grid are well explained [2].

The LV networks are undergoing radical changes; due to the integration of renewable based variable energy resources and Distributed Generations (DGs). For over 50 years, the concept of Flexible AC Transmission systems (FACTs) was introduced for the target of enhancing transfer of power and improvement of power quality. Eliminating power quality problems in the grid has been of great interest in the past decades because of the noticeable increase of sensitive loads. The FACTs devices, whether connected shunt, series or combined, mainly depend on reactive power sources. As mentioned before, there has been a massive increase of DGs whose interface is usually through static converters. These converters have shed the light on making use of them instead of traditional Static Compensators (STATCOMs). DGs converters can be controlled to supply both active and reactive power, raising the credibility of providing ancillary services. Active power is needed in voltage regulation if the phase angle is to be compensated too [3].

Single-phase loads set up most loads in LV networks, thus causing unbalance in voltage. Voltage unbalance in the presence of induction motors leads to the injection of high unbalanced currents, which in turn cause higher losses and heating effects [4]. Electronic converters (e.g. rectifiers) as a consequence of voltage unbalance will face a double line frequency harmonic component in the DC side. In addition, the uncontrolled power electronic loads will encounter even more harmonics [5]. Aside from unbalance problems, stated previously, the risk of these unbalanced currents in LV side being transferred to the MV grid is another issue. In this proposed scheme, power quality problems are mitigated at the Point of Common Coupling (PCC). A tertiary transformer can be used as a PCC between a WECS, MV grid and a LV load. The WECS serves as an active and reactive shunt connected power source controlled by its Back-to- back converter [6]. In addition to voltage regulation of LV load and unbalance detection and compensation, the WECS supplies the grid with balanced three phase power. Enhancing power quality in LV networks makes this system a potential to contribute in MV network management by providing ancillary services [4].

This paper is organized as follows; the description of grid-connected WECS is presented in Section 2. Analysis of control loops used for load voltage regulation and unbalance mitigation are explained in Section 3. The simulation results performed using PSCAD/EMTDC are discussed in Section 4. Section 5 includes the conclusion of the paper.

\section{System Description}

A 1.3 MW wind turbine is considered which is connected to the grid using back-to-back converters [7]. The generator used in the WECS is a PMSG. In cases of 
high wind speed, the wind turbine supplies a local load and the remaining output power is fed to the MV grid. In case of low wind speeds, the grid contributes with the wind turbine to supply the load. The WECS is connected to the grid through a transformer with a tertiary winding for local load connection as shown in Fig. 1.

Different topologies for hybrid transformers are presented [8]. The tertiary transformer is usually used in the application of inrush current mitigation of Line Frequency Transformer (LFT) as in [9], [10]. The tertiary transformer can also be used in filtering harmonics either with passive or active filters [11]. A hybrid transformer is designed in [12] to combine PV and wind turbine systems for MV grid-connected operation. In the system under study, the tertiary transformer replaces the need for two transformers; one for integrating the wind turbine with the MV grid and the other one for connecting the wind turbine and the local load.

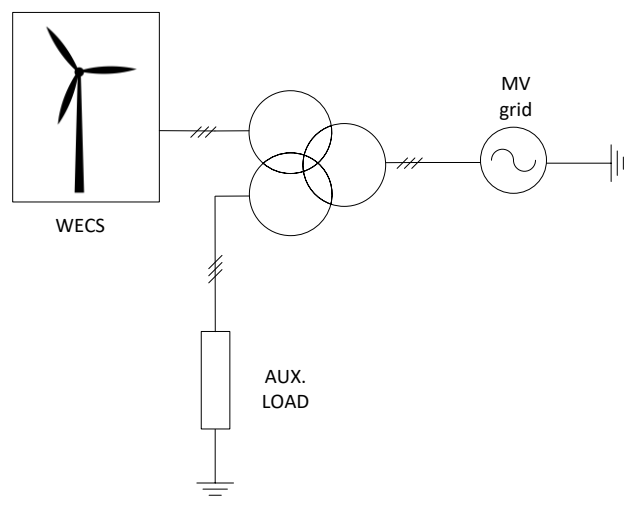

Fig. 1 The proposed system

The converter topology consists of two sides; the machine side converter and the grid side converter. The machine side converter is responsible for maximum power harvesting (MPPT) of the wind power. At each value of wind speed the wind turbine rotational speed $\omega$ is changed to track the peak of the "Power vs. rotational speed" $P-\omega$ curve.

The grid side converter is responsible for regulating the DC link voltage; hence protecting the electronic switches against any sudden voltage rises while delivering the extracted wind power to grid. In addition to this function, load voltage regulation at the tertiary winding and unbalance mitigating are proposed.

\section{Power Quality Enhancement}

Two power quality problems within the proposed system are discussed in the below sections.

\section{A. Voltage Regulation}

Different control algorithms are presented for voltage regulation using D-STATCOMs. Envelope tracking algorithms are used for tracking and compensation for voltage fluctuation [13]-[15]. Alternatively, Instantaneous Reactive Power (IRP) theory and Synchronous Reference Frame theory (SRF) are compared in [16], where SRF theory showed better performance in voltage regulation and compensating harmonic currents drawn by the load. In this paper, SRF theory is used for controlling both the DC link voltage of the back-to-back converter and AC load voltage connected to the tertiary winding. A PI controller is used to control the voltage of the DC link at a reference value by adjusting the active current of the grid-side converter as shown in Fig. 2(a). The DC voltage is measured and compared to the reference value then the output from the PI controller is considered as the $d$-axis current component, since it represents the active power command. A second PI controller is used to keep the load voltage constant by injecting reactive current. The control scheme is shown in Fig. 2(b), where the output of the load voltage controller is the reactive current, $q$-axis current component, to be injected by the grid-side converter.

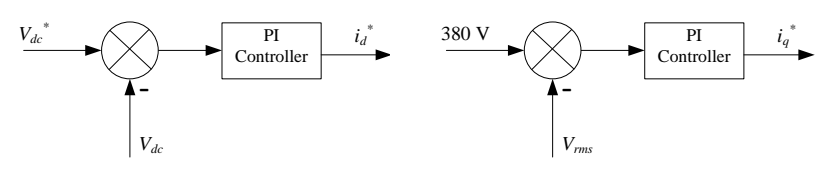

Fig. 2.(a) DC link voltage controller and (b) Load voltage regulation loop

The $d$ and $q$ currents are converted back to the threephase $a-b-c$ currents using inverse park's transformation,

$$
\begin{gathered}
{\left[\begin{array}{l}
i_{a} \\
i_{b} \\
i_{c}
\end{array}\right]=\frac{2}{3} C_{1}\left[\begin{array}{l}
i_{d} \\
i_{q} \\
i_{0}
\end{array}\right]} \\
C_{1}=\left[\begin{array}{ccc}
\sin (\theta) & \cos (\theta) & 1 \\
\sin \left(\theta-\frac{2 \pi}{3}\right) & \cos \left(\theta-\frac{2 \pi}{3}\right) & 1 \\
\sin \left(\theta+\frac{2 \pi}{3}\right) & \cos \left(\theta+\frac{2 \pi}{3}\right) & 1
\end{array}\right]
\end{gathered}
$$

The reference currents $\left(i_{a}, i_{b}, i_{c}\right)$ for tertiary winding voltage regulation and active power transfer to the grid will be used to obtain the gate pulses for the grid side converter using current control algorithm [17].

Regarding the reactive power capability of the converter, it is mainly dependent on the rating of the converter and the active power produced by the wind turbine [18]; as the following equation implies:

$$
Q=\sqrt{S_{c}^{2}-P_{w}^{2}}
$$

where $S_{c}$ is the converter rated apparent power and $P_{w}$ is the active power generated from the wind turbine. The reactive power is limited to a maximum of $15 \%$ of active power to avoid overloading the converter.

\section{B. Unbalance mitigation}

Various techniques are proposed to investigate current and voltage unbalance. The accuracy, response time, and ability to track the phase and frequency variations play a key role for the control system used to eliminate unbalance problems. Starting from the basic symmetrical components method which mainly depends on the current/voltage signal and a phase shift of it, which in case of a time varying signal and requiring an online estimation would be difficult [4], [19]. Another method is based on instantaneous reactive power theory which essentially depends on a balanced and sinusoidal supply voltage. Therefore, implementation of this method in practical lead 
to distorted control signals [20]. An improvement to the previous method is the SRF theory and notch/low pass filter, which is the most commonly used method. The drawback to this method is that it relies on the accuracy of PLL used to estimate frequency and phase angle required for abc-dq transformation [5], [21]. The Fast Fourier Transform (FFT) [22], Kalman Filter (KF) [23], MultiOutput Adaptive line combiner MO-ADALINE [24], neural network adaptive [25] detection methods are also used for the unbalance mitigation. In this paper, the Adaptive Notch Filter (ANF) based algorithm [26], [27] is proposed for unbalance mitigation. The performance of the proposed ANF is compared to the FFT based algorithm and SRF theory algorithm.

Fig. 3 illustrates a block diagram for the ANF algorithm which basically tracks the frequency of a specific sinusoidal component from the harmonics. This component could be taken out as an output. Considering three-phase system, three ANFs are deployed to provide the fundamental components $(a b c)_{f}$. ANFs are characterized by the following set of equations [26]:

$$
\begin{gathered}
\ddot{x}_{m}=-\theta^{2} x_{m}+2 \zeta_{m} \theta e_{m}(t), \quad m=a, b, c \\
e_{m}(t)=u_{m}(t)-\dot{x}_{m}
\end{gathered}
$$

where $u_{m}(t)$ is the input signal of the form $u_{m}(t)=$ $\sum_{i=1}^{n} A_{i} \sin \omega_{i} t+\phi_{i}, \quad i=1,2, \ldots n, \omega_{i}$ is the frequencies included in the signal while the fundamental frequency is $\omega_{o}, \theta$ is the estimate of the input signal frequency, $\zeta$ is a positive parameter which determines the depth of the notch. Since the three phases have the same frequency, all three phases contribute to the update law of $\theta$. Thus, the dynamic order of the three ANFs would be 7 instead of 9 if the frequency is to be estimated three times. The estimated frequency update law:

$$
\dot{\theta}=-\gamma \theta \sum_{m=a, b, c} x_{m} e_{m}(t)
$$

The dynamical system (3) and (4) has a unique periodic orbit located at

$$
P(t)=\left(\begin{array}{c}
P_{a}(t) \\
P_{b}(t) \\
P_{c}(t) \\
\theta
\end{array}\right)
$$

where $\theta=\omega_{o}$ and

$$
P_{m}(t)=\left(\begin{array}{l}
x_{m} \\
\dot{x}_{m}
\end{array}\right)=\left(\begin{array}{c}
-\frac{A_{m}}{\omega_{o}} \cos \left(\omega_{o} t+\delta_{m}\right) \\
A_{m} \sin \left(\omega_{o} t+\delta_{m}\right)
\end{array}\right)
$$

where $\dot{x}_{m} \equiv u_{f m}$ is the fundamental component of each phase estimated from the filter.

It can be noticed that $-\theta x_{m}$ is the $90^{\circ}$ phase shift of $\dot{x}_{m}$, hence the fundamental component and its $90^{\circ}$ phaseshift are the estimated parameters of the ANF for each phase. The following are equations of a linear transformation to obtain the symmetrical components,

$$
\begin{gathered}
u^{+}(t)=L_{2} U_{2}(t)+L_{1} U_{1}(t) \\
u^{-}(t)=L_{2} U_{2}(t)-L_{1} U_{1}(t) \\
u^{0}(t)=\left(I-2 L_{2}\right) U_{2}(t)
\end{gathered}
$$
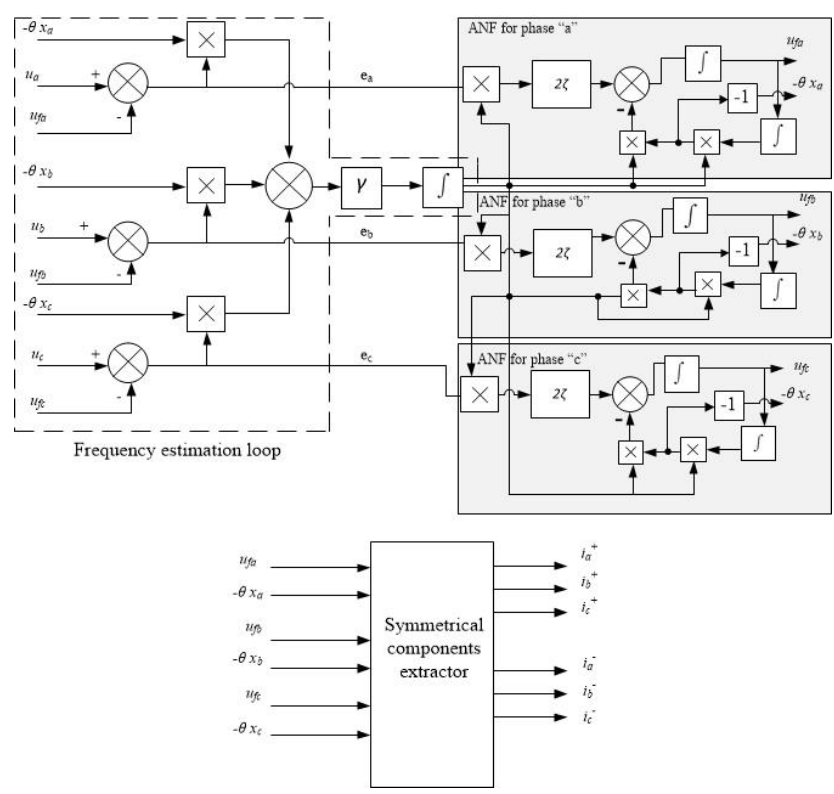

Fig. 3 Block diagram of the ANF algorithm for unbalance extraction

where, $\quad L_{1}=\frac{1}{2 \sqrt{3}}\left(\begin{array}{ccc}0 & 1 & -1 \\ -1 & 0 & 1 \\ 1 & -1 & 0\end{array}\right)$

$$
L_{2}=\frac{1}{3}\left(\begin{array}{ccc}
1 & -0.5 & -0.5 \\
-0.5 & 1 & -0.5 \\
-0.5 & -0.5 & 1
\end{array}\right)
$$

and $U_{1}(t), U_{2}(t)$ are obtained from ANF:

$$
U_{1}(t)=\left(\begin{array}{cc}
-\theta & x_{a} \\
-\theta & x_{b} \\
-\theta & x_{c}
\end{array}\right), \quad U_{2}(t)=\left(\begin{array}{c}
\dot{x}_{a} \\
\dot{x}_{b} \\
\dot{x}_{c}
\end{array}\right)
$$

The FFT based algorithm to estimate the negative sequence component of the load current is implemented on PSCAD, as shown in Fig. 4. The magnitude and phase angle of the negative sequence component, output from the FFT block, are used to construct the three-phase negative sequence currents. One drawback of this method is that it is not accurate when frequency changes.

The SRF based algorithm, shown in Fig. 5, includes a second order notch filter to reject the negative sequence component. The three-phase load currents $i_{l a}, i_{l b}, i_{l c}$ are transformed to $i_{d}, i_{q}, i_{0}$ components using the transformation $C_{1}$. It is worthy mentioned that the positive sequence component is a DC value, but the frequency of the negative sequence component is double line frequency component. The stop-band of the second order notch filter is set at double line frequency to reject the negative sequence component. The output positive sequence component is transformed back to $(a-b-c)$ frame and subtracted from the input signal to obtain the reference currents to compensate for the negative sequence $i_{a}^{-}, i_{b}^{-}, i_{c}^{-}$.The negative sequence currents components are added to $i_{a}, i_{b}, i_{c}$ currents components obtained from (1), to control DC link and load voltages, to obtain reference currents. Hysteresis current controller is used to provide gate pulses for the grid-side converter. 


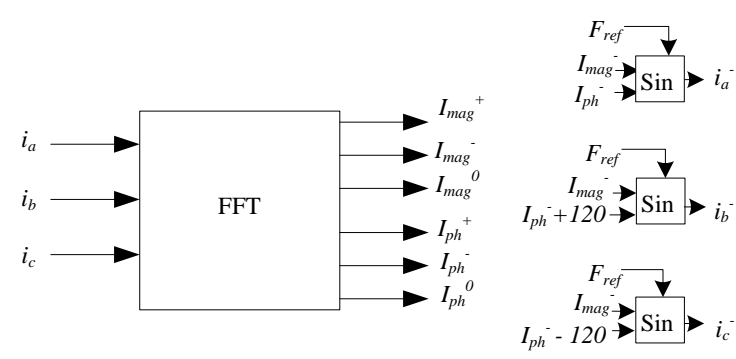

Fig. 4 FFT based algorithm for unbalance extraction

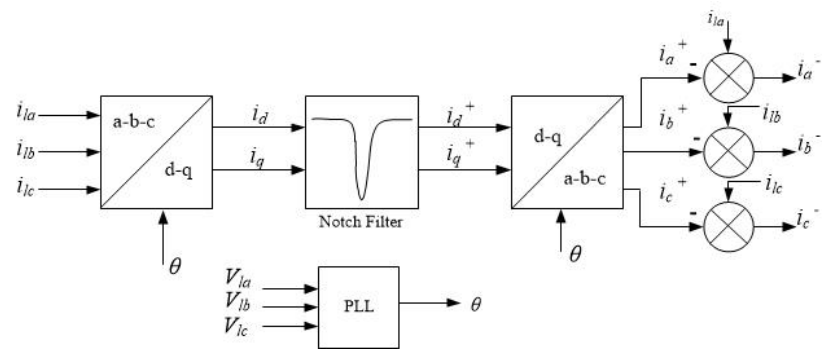

Fig. 5 SRF-PLL Unbalance extraction theory

\section{Simulation results}

The proposed control system for WECS to regulate tertiary winding voltage and unbalance mitigation is simulated on PSCAD/EMTDC program. Different case studies are conducted to evaluate the dynamic performance of the proposed WECS. Comparison of the ANF, the FFT and SRF methods used for unbalance mitigation are presented.

\section{A. WECS performance and Voltage regulation}

Table 1 illustrates the WECS model parameters. As shown in Fig. 6, the wind velocity changes from $5 \mathrm{~m} / \mathrm{s}$ to $13.4 \mathrm{~m} / \mathrm{s}$ at $t=6 \mathrm{~s}$, while the generator power changes from $69.3 \mathrm{~kW}$ to $1260 \mathrm{~kW}$ once the rotational speed of the generator reaches the new optimal setting. The DC link reference voltage is tightly regulated at $1.3 \mathrm{kV}$ as shown in Fig. 6(c). To keep DC link voltage, $i_{d}^{*}$ is changed from $0.23 \mathrm{kA}$ to $1.63 \mathrm{kA}$ as illustrated in Fig. 6(d). Fig. 7(a) and (b) shows the output active and reactive power from the WECS at the generator side and at the grid side. At the beginning, the wind speed is slow, so the output active power is low and extra power is needed to supply the load. As a result, the grid contributes with the WECS to supply the load. After $t=6 \mathrm{~s}$, when the wind speed increased to $13.4 \mathrm{~m} / \mathrm{s}$, due to inertia of the turbine the output power ramp up until it reaches nominal value at $t=7.6 \mathrm{~s}$. The output power from the WECS is high enough to supply the load, and the remaining power is transferred to the grid. Also, the reactive power provided by the WECS increases to compensate for the load voltage.

Table 1- System Parameters

\begin{tabular}{|l|c|}
\hline \hline $\begin{array}{l}\text { Tertiary transformer winding voltages } \\
\text { (MV grid, wind turbine \& local load) }\end{array}$ & $22,0.7,0.38 \mathrm{kV}$ \\
\hline PMSG voltage and power ratings & $0.7 \mathrm{kV}, 1.3 \mathrm{MW}$ \\
\hline DC link voltage & $1.3 \mathrm{kV}$ \\
\hline Frequency & $50 \mathrm{~Hz}$ \\
\hline
\end{tabular}
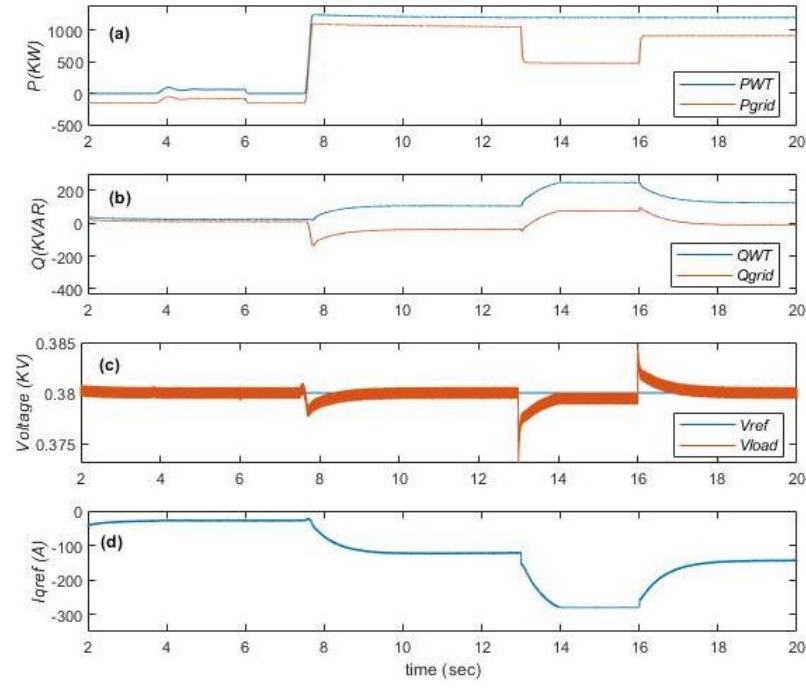

Fig. 6 (a) Wind speed (b) Generator speed (c) DC link voltage (d) $i_{d} *$ of the grid side converter.
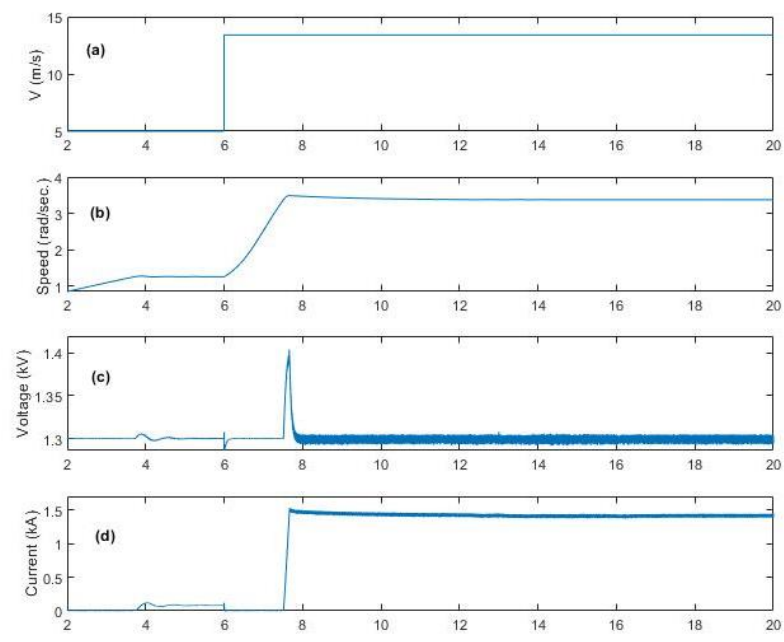

Fig. 7 (a),(b) Active and reactive power at the WECS and grid sides, (c) load voltage, and $(d) i_{q}^{*}$ of the grid side converter.

To examine the dynamic performance of the load voltage control loop, the load is increased at $t=13 \mathrm{~s}$, then is reduced to $50 \%$ at $t=16 \mathrm{~s}$. Fig. 7 (c) demonstrates tight load voltage regulation by controlling $i_{q}^{*}$ as illustrated in Fig. 7(d). As expected, when the load increases, $13 \mathrm{~s}<t<16 \mathrm{~s}$, the active power delivered to grid reduces. In addition, the reactive current of the grid-side converter increases to regulate the load. It can be noticed that $i_{q}^{*}$ is limited to a value such that the reactive power doesn't exceed $15 \%$ of the active power supplied by the WECS. When the load is reduced at $t=16 \mathrm{~s}$, the load voltage rises and $i_{q}^{*}$ is decreased to keep the load voltage at the set value, $380 \mathrm{~V}$.

\section{B. Negative sequence extraction and Unbalance mitigation}

This section is dedicated to compare the dynamic performance of the ANF to extract the negative and positive sequence components with the FFT and the SRF methods. An unbalance load of $46 \%$ is connected to the system at $t=8 \mathrm{~s}$ and the unbalance factor is reduced to $30 \%$ 
at $t=15$ s. Fig. 9(a) shows the negative sequence component of phase ' $a$ ' obtained using the ANF, SRF, and FFT methods. It can be observed that the ANF converges faster than the SRF and FFT methods. The FFT is the slowest in response. The estimated positive sequence component is shown in Fig. 8(b) where the ANF also shows the fastest response in detecting the change in the sequence components at $8 \mathrm{sec}$. Fig. 9(a) and (b) demonstrate the estimated negative and positive sequence components during the transition from $46 \%$ load unbalance to $30 \%$ load unbalance. It is clear, that the ANF extracts the symmetrical components smoothly and faster than the other methods. The results reveals that the dynamic performance of the ANF outdoes the conventional methods.
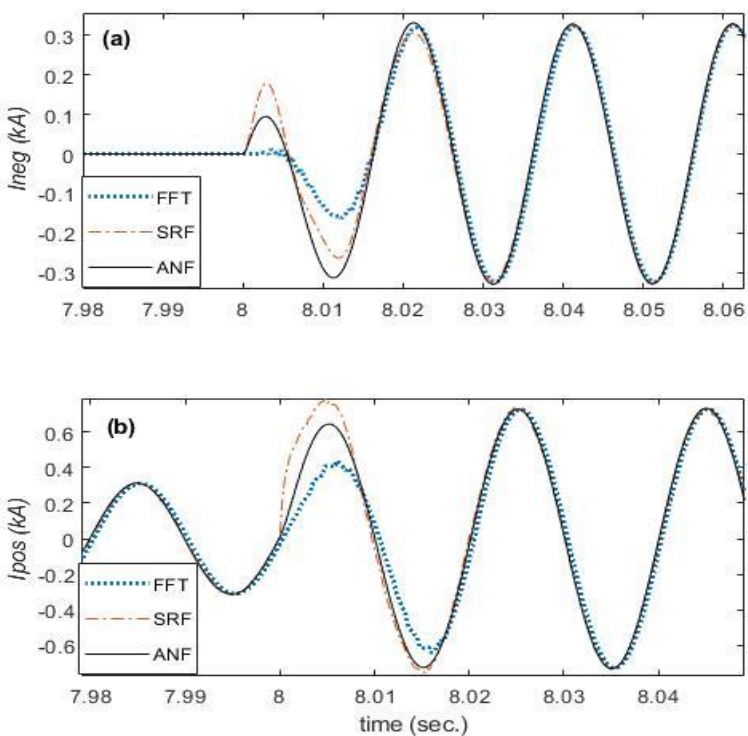

Fig. 8 (a) Negative sequence component and (b) positive sequence component of phase a at $46 \%$ unbalance
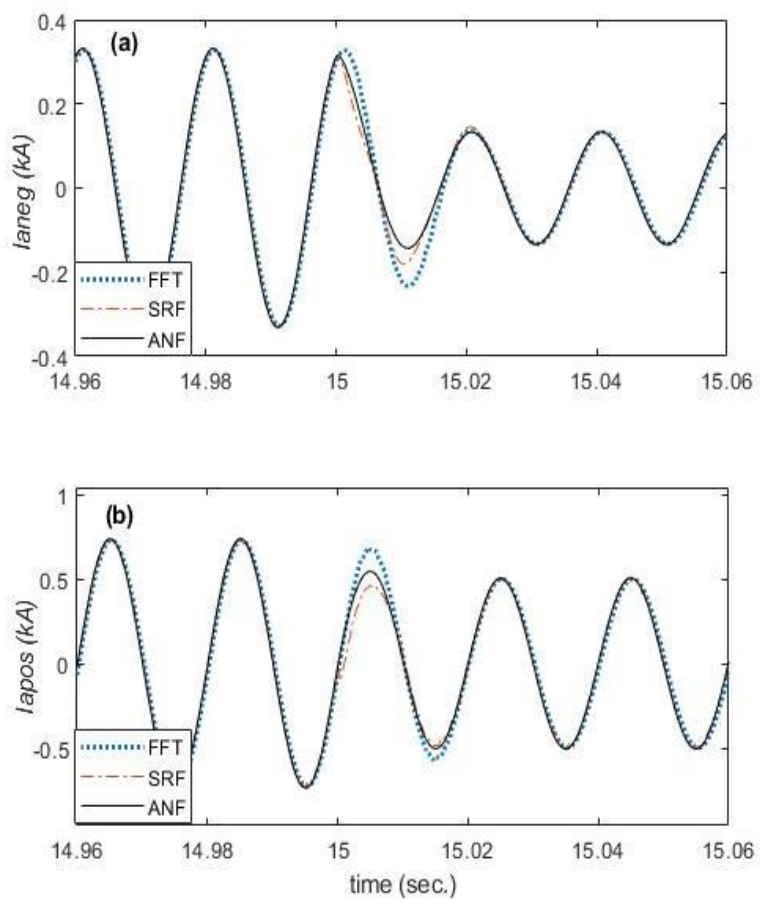

Fig. 9(a) Negative sequence component and (b) positive sequence component of phase a at $30 \%$ unbalance
The compensation for unbalance is enabled from $t=10 \mathrm{~s}$ to $t=17$ s. Fig. 10(a) illustrates the grid currents at $46 \%$ load unbalance just before enabling the unbalance mitigation control loop and after enabling it at $t=10 \mathrm{~s}$. It is obvious that the proposed ANF succeeds to balance the grid current while the load current remains unchanged as demonstrated in Fig 10(b). Fig. 11(a) shows the grid currents at $30 \%$ load unbalance where the unbalance mitigation loop is disabled at at $t=17 \mathrm{~s}$ to evaluate the dynamic performance of the system. As expected, the load current is not affected by the unbalance mitigation loop as shown in Fig.11(b).
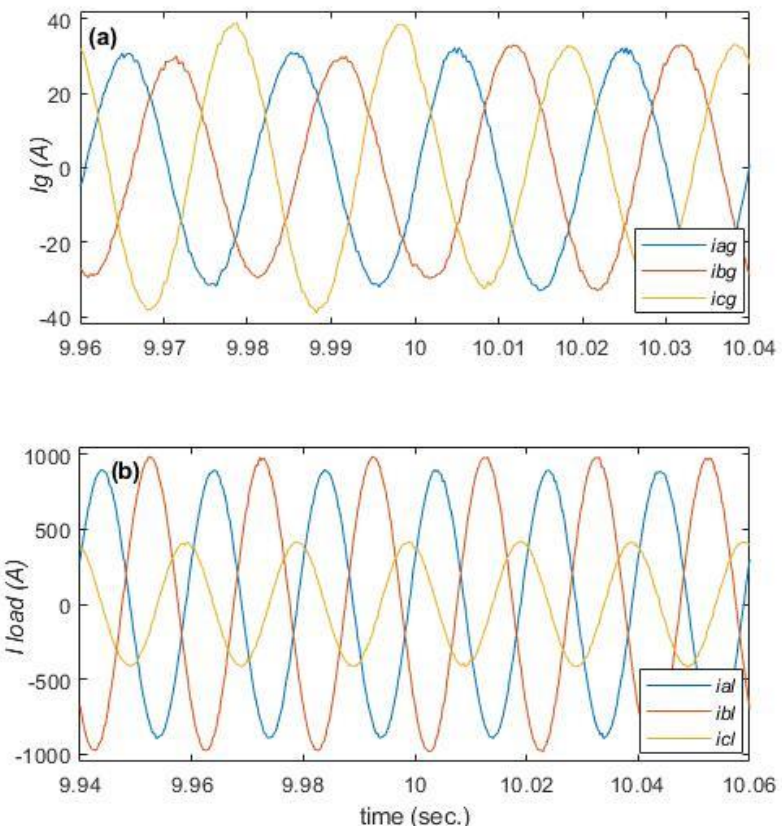

Fig. 10 (a) three-phase grid currents at $46 \%$ unbalance (b) three-phase grid currents at $46 \%$ unbalance
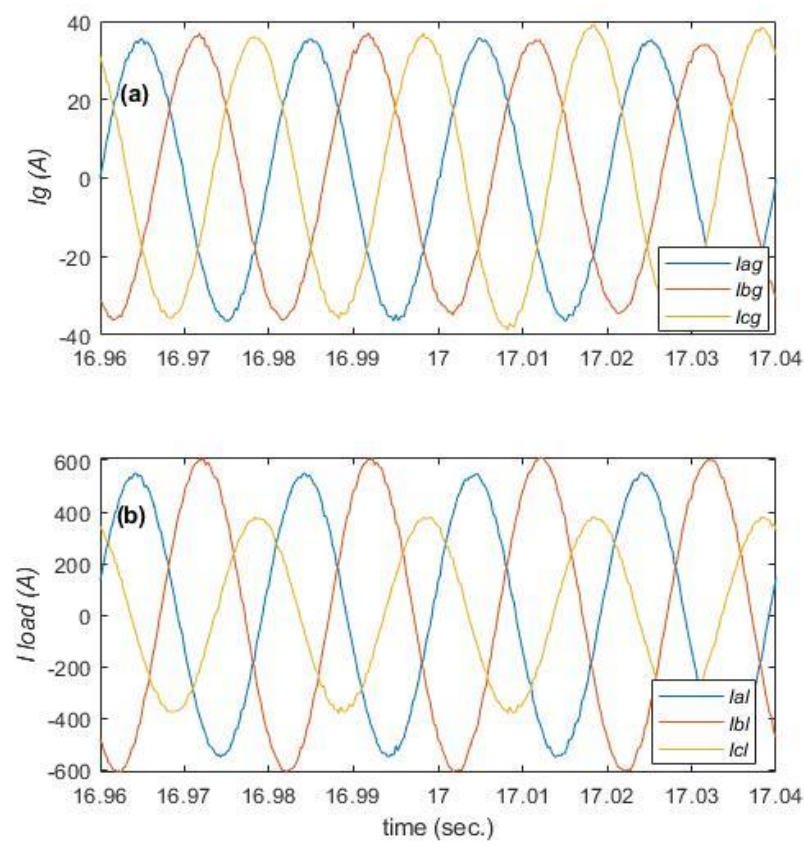

Fig. 11 (a) three-phase grid currents at $30 \%$ unbalance (b) threephase grid currents at $30 \%$ unbalance 


\section{Conclusion}

This paper presents control loop for WECS to improve power quality level by regulating the voltage at the tertiary winding of the interfacing transformer and mitigating load unbalance. Voltage regulation of the local connected load is tested under different loading conditions and voltage level is maintained at its desired level. Unbalance mitigation is investigated using three different sequence components estimation methods. The ANF exhibits the best performance over the SRF and the FFT in convergence speed, adding to its unique feature of detecting the system frequency. The ANF is used in the control loop of unbalance mitigation and the grid current is accurately balanced at different load unbalance conditions.

\section{REFERENCES}

[1] X. Tan, J. Dai, and B. Wu, "A novel converter configuration for wind applications using PWM CSI with diode rectifier and buck converter,"IEEE International Electr ic Machines \& Drives Conference (2011), pp. 359-364

[2] M. I. Marei, A. Mohy, and A. A. El-Sattar "An Integrated Control System for Sparse Matrix Converter Interfacing PMSG with the Grid," International Journal of Electrical Power \& Energy Systems (2015), Vol. 73, pp. 340-349.

[3] Rong Cai, M. Bongiorno and A. Sannino, "Control of DSTATCOM for voltage dip mitigation," International Conference on Future Power Systems (2005) pp. 6 pp.-6.

[4] M. Coppo, A. Raciti, R. Caldon and R. Turri, "Exploiting inverter-interfaced DG for Voltage unbalance mitigation and ancillary services in distribution systems," IEEE 1st International Forum on Research and Technologies for Society and Industry Leveraging a better tomorrow (2015),pp. 371-376.

[5] L. Xu, Z. Miao, L. Fan and G. Gurlaskie, "Unbalance and harmonic mitigation using battery inverters," 2015 North American Power Symposium (2015) pp. 1-6.

[6] M. I. Marei, T. El-Fouly, E. F. El-Saadany and M. M. A. Salama, "A Flexible Wind Energy Scheme for Voltage Compensation and Flicker Mitigation," IEEE Proceeding of General Meeting (2003), Toronto, Canada.

[7] M.I. Marei and H. El-Goharey, "Modeling and Dynamic Analysis of Gearless Variable-Speed Permanent Magnet Synchronous Generator Based Wind Energy Conversion System" Renewable Energy and Power Quality Journal (2012), Vol. 10, pp. 1597-1602.

[8] J. Burkard and J. Biela, "Evaluation of topologies and optimal design of a hybrid distribution transformer,"17th European Conference on Power Electronics and Applications(2015),pp.1-10.

[9] J. Burkard and J. Biela, "Transformer inrush current mitigation concept for hybrid transformers,"19th European Conference on Power Electronics and Applications (2017), pp. P.1-P.9.

[10] D. P. Balachandran, R. S. Kumar and V. P. Shimnamol, "Transformer Inrush Current Reduction by Power Frequency Low Voltage Signal Injection to the Tertiary Winding," IEEE Lausanne Power Tech (2007), pp. 1953-1958.

[11] A. Mishal Abd-Elrasool Elagab and I. Mohamad El-Amin, "Minimization of Harmonics Penetration into Transmission and Distribution Systems by Utilizing Tertiary Winding of the Transformer,"9th IEEE-GCC Conference and Exhibition (2017), pp. 1-9.

[12] B. C. Sujatha, T. V. Ramaswamy, R. R. Prabhu, N. Sumana, D. M. U and S. Z. Ismail, "Design of 100kVA energy efficient three phase hybrid transformer for combined application of solar and wind," 4th International Conference for Convergence in Technology (2018), pp. 1-4.

[13] M. I. Marei, E. F. El-Saadany and M. M. A. Salama, "An Intelligent Control for the DG Interface to Mitigate Voltage Flicker," 18th IEEE Applied Power Electronics Conference (2003), Florida, USA.

[14] M. I. Marei, "A unified control strategy based on phase angle estimation for matrix converter interface system," IEEE Systems Journal (2012), Vol. 6, No. 2, pp. 278-286.

[15] M. I. Marei, E. F. El-Saadany, and M. M. A. Salama, "Experimental evaluation of envelope tracking techniques for voltage disturbances," Electric Power Systems Research (2010), Vol. 80, No. 3, pp. 339 - 344.

[16] S. P. Gopal and D. R. Patil, "Hysteresis Band Current Controller for voltage regulation and harmonic mitigation using DSTATCOM," International Conference on Computation of Power, Energy Information and Commuincation Chennai (2016), pp. 707-712

[17] M. I. Marei, E. F. El-Saadany and M. M. A. Salama, “A Novel Control Scheme for STATCOM Using Space Vector Modulation Based Hysteresis Current Controller," 11th International Conference on Harmonics and Quality of Power (2004), USA.

[18] A. R. Malekpour, A. Pahwa and S. Das, "Inverter-based var control in low voltage distribution systems with rooftop solar PV," North American Power Symposium (2013), Manhattan, KS, 2013, pp. 1-5.

[19] W. Lyu et al., "A Novel Three Phase Unbalance Detection and Compensation method of Active Power Filter," Chinese Automation Congress (2018), pp. 418-422.

[20] R. S. Herrera, P. SalmerÓn and H. Kim, "Instantaneous Reactive Power Theory Applied to Active Power Filter Compensation: Different Approaches, Assessment, and Experimental Results," in IEEE Transactions on Industrial Electronics (2008), vol. 55, no. 1, pp. 184-196.

[21] Anu P, Divya R and M. G. Nair, "STATCOM based controller for a three phase system feeding single phase loads," International Conference on Technological Advancements in Power and Energy (2015), pp. 333-338.

[22] Z. Wang, Y. Li and H. Zhang, "Harmonic Detection Method Based on Windowed Double-Spectrum Interpolation FFT," International Conference on Robots \& Intelligent System (2019), pp. 425-427.

[23] M. Sun and Z. Sahinoglu, "Extended Kalman filter based grid synchronization in the presence of voltage unbalance for smart grid," ISGT (2011), Anaheim, CA, pp. 1-4.

[24] M. I. Marei, E. F. El-Saadany and M. M. A. Salama, "A processing unit for symmetrical components and harmonics estimation based on a new adaptive linear combiner structure," in IEEE Transactions on Power Delivery (2004), vol. 19, no. 3, pp. $1245-1252$.

[25] L. S. Xavier, A. F. Cupertino, V. F. Mendes and H. A. Pereira, "Detection method for multi-harmonic current compensation applied in three-phase photovoltaic inverters," 12th IEEE International Conference on Industry Applications (2016), pp. 1-8.

[26] D. Yazdani, M. Mojiri, A. Bakhshai and G. JoÓs, "A Fast and Accurate Synchronization Technique for Extraction of Symmetrical Components," in IEEE Transactions on Power Electronics (2009), vol. 24, no. 3, pp. 674-684.

[27] A. A. Abu El-Naga, M. I. Marei, and H. S. K. El-Goharey, "Second Order Adaptive Notch Filter Based Wind Power Smoothing Using Flywheel Energy Storage System," 19th IEEE International Middle East Power Systems Conference (2017), pp. 314-319. 